\title{
Crescimento e fenologia de espécies de Jatropha durante a estação chuvosa
}

\author{
Messias F. de Queiroz'1, Pedro D. Fernandes², José Dantas Neto ${ }^{3}$, \\ Nair H. C. Arriel ${ }^{4}$, Francisco J. L. Marinho ${ }^{1} \&$ Saulo F. Leite ${ }^{1}$
}

\begin{abstract}
RESUMO
Jatropha curcas L., Jatropha mollissima (Pohl) Baill e Jatropha gossypiifolia L. são Euforbiáceas com potencial para produção de biodiesel e uso na indústria farmacêutica e em cosméticos. Objetivou-se, com este trabalho, avaliá-las em termos de crescimento e fenologia em pesquisa de campo. Adotou-se o delineamento experimental em blocos casualisados contendo na parcela 18 plantas e tendo área útil de $15 \mathrm{~m}^{2}$. Nos estudos fenológicos das plantas foram consideradas as seguintes fases: estabelecimento/ crescimento vegetativo, floração, frutificação e maturação/colheita. As fases fenológicas das espécies diferiram cronologicamente. Jatropha mollissima cresceu mais do que as outras espécies em altura de plantas enquanto Jatropha curcas cresceu mais em diâmetro caulinar. As maiores taxas de crescimento relativo em altura de plantas ocorreram durante o crescimento vegetativo com os maiores valores sendo registrados em Jatropha mollissima enquanto as maiores taxas de crescimento relativo, também no crescimento vegetativo, foram registradas em Jatropha curcas. As menores taxas de crescimento relativo em altura de plantas e diâmetro caulinar das espécies estudadas coincidiram com as fases reprodutivas.
\end{abstract}

Palavras-chave: Euforbiácea, oleaginosas, ciclo fenológico, altura de planta, diâmetro de caule

\section{Growth and phenology of species of Jatropha during the rainy season}

\begin{abstract}
Jatropha curcas L., Jatropha mollissima (Pohl) Baill and Jatropha gossypiifolia L. are Euphorbiaceae with potential for biodiesel production and use in pharmaceutical and cosmetic industries. The aim of this study was to evaluate these species in terms of growth and phenology in a field experiment. In this study an experimental design of randomized blocks was adopted. The experimental plot had 18 plants and a useful plot area of $15 \mathrm{~m}^{2}$. In the phenological studies of plants the following phases were considered: establishment/ vegetative growth, flowering, fruiting and ripening/harvest. The phenological stages of the species differed chronologically. Jatropha mollissima outgrew the others in plant height, while Jatropha curcas outgrew the others in stem diameter. The highest relative growth rates in plant height occurred during vegetative growth, with the highest values being recorded in Jatropha mollissima, while the greatest relative growth rates also in vegetative growth were recorded in Jatropha curcas. The lowest relative growth rates in plant height and stem diameter of the studied species coincided with the reproductive phases.
\end{abstract}

Key words: Euphorbiaceae, oil seeds, phenological cycle, plant height, stem diameter

'DAA/UEPB, Sítio Imbaúba, s/n, Zona Rural, CEP 58117-000, Lagoa Seca, PB. (83) 3366-1244. E-mail: messias@uepb.edu.br, chicohare@yahoo.com.br, saulo_fleite@yahoo.com.br

2 PRPGP/UEPB, UAEA/UFCG, Rua Antonio Joaquim Pequeno, 800, CEP 58429-105, Campina Grande, PB. Fone: (83) 8824-1448. E-mail: pdantas@pq.cnpq.br

3 UAEA/UFCG, Av. Amazonas, 465, Liberdade, CEP 58414-530, Campina Grande, PB. Fone: (83) 2101-1185. E-mail: zedantas1955@gmail.com

${ }^{4}$ Embrapa Algodão, Rua Osvaldo Cruz, 1143, Centenário, C.P. 174, CEP 58428-095, Campina Grande, PB. Fone: (83) 3182-4300. E-mail: nair.arriel@embrapa.br 


\section{INTRODUÇÃO}

O Governo Federal do Brasil criou, em 2002, o Programa Brasileiro de Biocombustíveis (Probiodiesel), com o objetivo de reduzir a dependência do petróleo, expandir os mercados das oleaginosas, impulsionar a demanda por combustíveis alternativos e reduzir a emissão de gases poluentes (Urquiaga et al., 2005).

No período de 2002-2010 o Probiodiesel passou por reformulações sendo denominado, em 2004, Programa Nacional de Produção e Uso do Biodiesel (PNPB). As adequações foram realizadas para dar um caráter de inclusão social ao programa através da participação de setores ativos da sociedade especialmente dos agricultores familiares, e ampliar a capacidade de geração de emprego e de renda.

Entre as várias espécies com potencial de serem exploradas como fonte de óleo para produção de energia alternativa, incluem-se as do gênero Jatropha, sendo mais citada a Jatropha curcas L., denominada pinhão-manso (Arruda et al., 2004; Francis et al., 2005); outras duas espécies existem, o pinhão-bravo [Jatropha mollissima (Pohl) Baill] e o pinhãoroxo (Jatropha gossypiifolia L.), ocorrendo naturalmente no Nordeste brasileiro, adaptadas às suas condições climáticas.

As três espécies são plantas arbustivas da família Euforbiaceae, nativas na América do Sul, de crescimento rápido, podendo chegar a $5 \mathrm{~m}$ de altura e diâmetro de $20 \mathrm{~cm}$, em condições favoráveis de clima e solo, ocorrendo também na América Central, África e Ásia (Augustus et al., 2002; Francis et al., 2005). São comumente encontradas vegetando em vários estados brasileiros; em áreas semiáridas se revestem de elevada importância pelas possibilidades de fácil cultivo, adaptação a solos pouco férteis, degradados e pela tolerância à seca (Albuquerque \& Andrade, 2002).

De modo geral, as três espécies de Jatropha foram pouco pesquisadas existindo alguns trabalhos sobre o pinhão-manso e nada sendo encontrado, na literatura disponível, envolvendo estudos com pinhão-bravo e roxo. Em geral, os trabalhos com Jatropha curcas versam sobre efeitos de estresse abiótico (Nery, 2008; Nery et al., 2009; Silva, 2009; Silva et al., 2011; Veras et al., 2011). Em relação à fenologia encontrou-se uma referência com descrição das fases do ciclo das plantas de pinhão-manso, durante um ano, em Rio Largo, Alagoas (Santos, 2008). Estudos de fenologia são relevantes para se avaliar o crescimento e a reprodução das espécies, avaliar os efeitos de interações com fatores do clima bem como para o manejo de cultivos e para programas de melhoramento (Fisch et al., 2000; Folgarait et al., 2007).

Considerando a carência de estudos com espécies de Jatropha objetivou-se, com este trabalho, avaliar o crescimento e determinar as fases fenológicas de pinhão-manso, pinhãobravo e pinhão-roxo, em cultivo durante a estação chuvosa.

\section{Material e Métodos}

O experimento foi desenvolvido em condições de campo durante a estação chuvosa de abril a setembro de 2009, em área agrícola pertencente ao Centro de Ciências Agrárias e Ambientais (CCAA), Campus II da Universidade Estadual da
Paraíba (UEPB), Lagoa Seca, PB, com as seguintes coordenadas geográficas: latitude $7^{\circ} 09^{\prime} \mathrm{S}$; longitude $35^{\circ} 52^{\prime} \mathrm{W}$ e altitude de $634 \mathrm{~m}$.

O clima, segundo a classificação de Köppen, é do tipo AS, ou seja, tropical com estação seca, com médias, durante o período de estudos, de temperatura em torno de $22{ }^{\circ} \mathrm{C}$ sendo a mínima de $19^{\circ} \mathrm{C}$ e a máxima de $26^{\circ} \mathrm{C}$, precipitação acumulada durante os meses da pesquisa de $782,50 \mathrm{~mm}$, com maiores índices pluviométricos concentrados nos meses de abril a agosto; a evapotranspiração de referência acumulada foi $542,69 \mathrm{~mm}$ e umidade relativa média de $91 \%$, durante a pesquisa.

No experimento foram estudadas três espécies de pinhão: pinhão-manso (Jatropha curcas L.), pinhão-bravo [Jatropha mollissima (Pohl) Baill] e pinhão-roxo (Jatropha gossypiifolia L.). O delineamento experimental foi em blocos ao acaso, com quinze repetições sendo a parcela constituída de 18 plantas $(9 \mathrm{x}$ 7,5 m), com área de $67,5 \mathrm{~m}^{2}$ e área útil de $15 \mathrm{~m}^{2}$ (4 plantas úteis).

Antes do plantio foram realizadas adubações de fundação com fontes de nitrogênio (sulfato de amônio) e matéria orgânica (esterco bovino curtido), fosfato de rocha e rocha potássica. As adubações químicas (N-P-K) e orgânicas foram baseadas nas análises de solo aplicando-se 40-30-30 kg ha-1 de N-P-K. Fósforo, na forma de superfosfato simples $\left(18 \% \mathrm{de}_{2} \mathrm{O}_{5}\right)$ e K, na forma de cloreto de potássio $\left(60 \%\right.$ de $\left.\mathrm{K}_{2} \mathrm{O}\right)$, foram aplicados no plantio adicionando-se, também, mais $10 \mathrm{~L}$ de esterco bovino seco e curtido. Nitrogênio, na forma de sulfato de amônio $(20,5 \%$ de $N)$, foi parcelado em duas vezes em cobertura, aos 120 e 150 dias após o transplantio, seguindo-se procedimentos contidos em Nery (2008).

A semeadura foi realizada em 31/01/2009 após seleção rigorosa das sementes eliminando-se as defeituosas e danificadas. As mudas foram formadas em sacos de polietileno preto, com capacidade de $0,125 \mathrm{~m}^{3}$, com furos laterais e na base contendo, como substrato, material de solo arenoso do local da pesquisa e esterco bovino na proporção $3: 1$, sendo irrigadas diariamente.

Para prevenção de problemas nutricionais, principalmente de micronutrientes, realizaram-se adubações foliares uma vez por mês, a partir do início da frutificação, com fertilizante foliar contendo NPKMg (15-5-30-3) + micronutrientes (B, Cu, Fe, $\mathrm{Mn}$, Mo e $\mathrm{Zn}$ ) na dose de $10 \mathrm{~g} \mathrm{~L}^{-1}$ de água.

$\mathrm{O}$ transplantio das mudas foi realizado no período chuvoso (01/04/2009), aos 60 dias após a semeadura (DAS) em covas com abertura de $50 \times 50 \mathrm{~cm}$ e $50 \mathrm{~cm}$ de profundidade obedecendo ao espaçamento de 1,5 m entre plantas na mesma linha e $2,5 \mathrm{~m}$ entre fileiras de plantas.

Os tratamentos fitossanitários visaram ao controle de ácaro branco (Polyphagotarsonemus latus) e vermelho (Tetranychus desertorum), percevejo (Pachycoris torridus), cigarrinha verde (Empoasca kraemeri) e formiga cortadeira, as principais pragas do pinhão (Nery, 2008). O controle da vegetação espontânea foi feito periodicamente eliminando-se o mato sob as plantas e se roçando entre plantas, dispondo a vegetação espontânea arrancada e cortada sob as copas.

O solo da área do experimento, classificado como Neossolo Regolítico Eutrófico (EMBRAPA, 2009), é declivoso (até 15\%), profundo, de textura arenosa, com boa drenagem e de fertilidade moderada (Tabela 1). 
Tabela 1. Atributos físico-hídricos e químicos de amostras de solo no início da pesquisa, em duas profundidades

\begin{tabular}{|c|c|c|c|}
\hline \multirow{2}{*}{ Características } & \multirow{2}{*}{ Unidade } & \multicolumn{2}{|c|}{ Profundidade (cm) } \\
\hline & & 0 a 20 & 20 a 40 \\
\hline \multicolumn{4}{|l|}{ Físico-hídrica } \\
\hline Areia & $\mathrm{g} \mathrm{kg}^{-1}$ & 871,07 & 884,47 \\
\hline Silte & $\mathrm{g} \mathrm{kg}^{-1}$ & 87,13 & 73,70 \\
\hline Argila & $\mathrm{g} \mathrm{kg}^{-1}$ & 41,80 & 41,80 \\
\hline Classificação textural & - & $\mathrm{FA}^{*}$ & $F A^{*}$ \\
\hline Densidade do solo (ds) & $\mathrm{g} \mathrm{cm}^{-3}$ & 1,49 & 1,48 \\
\hline Densidade das partículas (dp) & $\mathrm{g} \mathrm{cm}^{-3}$ & 2,75 & 2,73 \\
\hline Porosidade $(\varepsilon)$ & $\%$ & 45,84 & 45,62 \\
\hline $\begin{array}{l}\text { Capacidade de campo } \\
(10,13 \mathrm{kPa})(\mathrm{CC})\end{array}$ & $\mathrm{g} \mathrm{kg}^{-1}$ & 95,93 & 121,50 \\
\hline $\begin{array}{l}\text { Ponto de murchamento } \\
(1519.87 \mathrm{kPa})(\mathrm{PM})\end{array}$ & $\mathrm{g} \mathrm{kg}^{-1}$ & 50,53 & 51,53 \\
\hline Água disponível (AD) & $\mathrm{g} \mathrm{kg}^{-1}$ & 45,40 & 70,00 \\
\hline \multicolumn{4}{|l|}{ Complexo sortibo } \\
\hline Cálcio - Ca & $\mathrm{cmol}_{\mathrm{c}} \mathrm{dm}^{-3}$ & 3,50 & 3,10 \\
\hline Magnésio -Mg & $\mathrm{cmol}_{\mathrm{c}} \mathrm{dm}^{-3}$ & 2,53 & 2,12 \\
\hline Sódio - Na & $\mathrm{cmol}_{\mathrm{c}} \mathrm{dm}^{-3}$ & 0,02 & 0,02 \\
\hline Potássio - K & $\mathrm{cmol}_{\mathrm{c}} \mathrm{dm}^{-3}$ & 0,26 & 0,19 \\
\hline Soma de bases - S & $\mathrm{cmol}_{\mathrm{C}} \mathrm{dm}^{-3}$ & 6,28 & 5,44 \\
\hline Hidrogênio & $\mathrm{cmol}_{\mathrm{c}} \mathrm{dm}^{-3}$ & 2,07 & 2,47 \\
\hline Alumínio & $\mathrm{cmol}_{\mathrm{c}} \mathrm{dm}^{-3}$ & 0,00 & 0,07 \\
\hline Capacidade de troca catiônica & $\mathrm{cmol}_{\mathrm{c}} \mathrm{dm}^{-3}$ & 8,34 & 8,14 \\
\hline Carbonato de Cálcio & $\%$ & Ausência & Ausência \\
\hline Carbono orgânico & $\mathrm{gkg}^{-1}$ & 1,19 & 0,93 \\
\hline Matéria orgânica - M.0. & $\mathrm{g} \mathrm{kg}^{-1}$ & 2,05 & 1,61 \\
\hline Nitrogênio - N & $\mathrm{g} \mathrm{kg}^{-1}$ & 0,11 & 0,09 \\
\hline Fósforo assimilável - P & $\mathrm{mg} \mathrm{dm}{ }^{-3}$ & 5,64 & 5,49 \\
\hline $\mathrm{pH}$ em água $(1: 2,5)$ & - & 6,14 & 6,01 \\
\hline $\begin{array}{l}\text { Condutividade elétrica suspensão } \\
\text { solo-água }(1: 2,5) \text { (CEsa) }\end{array}$ & $\mathrm{dS} \mathrm{m}^{-1}$ & 0,14 & 0,13 \\
\hline
\end{tabular}

${ }^{*}$ FA - Franco-arenoso

Para determinação da fenologia do pinhão-manso, bravo e roxo realizaram-se, diariamente, vistorias nas parcelas experimentais até ser possível identificar as diferentes fases fenológicas para cada uma das três espécies de Jatropha estudadas. O número de dias caracterizando as fases fenológicas, foi determinado a partir da média aritmética dos resultados registrados nas vistorias realizadas nos três blocos experimentais, adaptandose critérios contidos em Nery (2008) e se considerando: fase I (Estabelecimento/crescimento vegetativo) compreendida a partir do transplantio das mudas no campo até o dia anterior ao início da floração; fase II (Floração): compreendida a partir do surgimento das primeiras inflorescências até o início da frutificação; fase III (Frutificação): formação dos primeiros frutos até o início de maturação dos frutos; fase IV (Maturação/Colheita): período de maturação e colheita dos frutos, compreendida pelo final da fase III até a colheita.

As avaliações de altura das plantas em cm (AP) e diâmetro caulinar em $\mathrm{mm}$ (DC) foram realizadas nas quatro plantas úteis da parcela experimental, aos $15,45,75,105,135$ e 165 DAT. A altura de planta foi medida em $\mathrm{cm}$ entre o colo da planta e a gema localizada na extremidade do ramo mais alto, com auxílio de uma trena fixada em um cano de PVC rígido; o diâmetro do caule foi avaliado com paquímetro digital (mm), a nível do colo das plantas.

As taxas de crescimento foram estimadas a partir dos dados de AP e de DC obtendo-se as taxas de crescimento relativo em altura $\left(\mathrm{TCR}_{\mathrm{AP}}\right)$ e em diâmetro $\left(\mathrm{TCR}_{\mathrm{DC}}\right)$ nos períodos $\left(\mathrm{T}_{1}-\mathrm{T}_{2}\right)$ 15-45, 45-75, 75-105, 105-135 e 135-165 DAT, conforme as Eqs. 1 e 2, a seguir, descritas em Benincasa (2003):

$$
\begin{aligned}
\mathrm{TCR}_{\mathrm{AP}} & =\frac{\ln \mathrm{AP}_{2}-\ln \mathrm{AP}_{1}}{\mathrm{~T}_{2}-\mathrm{T}_{1}} \\
\mathrm{TCR}_{\mathrm{DC}} & =\frac{\ln \mathrm{DC}_{2}-\ln \mathrm{DC}_{1}}{\mathrm{~T}_{2}-\mathrm{T}_{1}}
\end{aligned}
$$

em que:

$\mathrm{TCR}_{\mathrm{AP}}$ - taxa de crescimento relativo em altura de plantas $\left(\mathrm{cm} \mathrm{cm}^{-1} \mathrm{~d}^{-1}\right)$

$\mathrm{AP}_{1}$ - altura da planta no tempo $\mathrm{T}_{1}(\mathrm{~cm})$

$\mathrm{AP}_{2}$ - altura da planta no tempo $\mathrm{T}_{2}(\mathrm{~cm})$

$\mathrm{TCR}_{\mathrm{DC}}$ - taxa de crescimento relativo caulinar em diâmetro $\left(\mathrm{mm} \mathrm{mm}^{-1} \mathrm{~d}^{-1}\right)$

$\mathrm{DC}_{1}$ - diâmetro do caule no tempo $\mathrm{T}_{1}(\mathrm{~mm})$

$\mathrm{DC}_{2}$ - diâmetro do caule no tempo $\mathrm{T}_{2}(\mathrm{~mm})$

$\mathrm{T}_{1} \quad$ - início do período de determinação da taxa de crescimento relativo

$\mathrm{T}_{2}$ - final do período de determinação da taxa de crescimento relativo

ln - logaritmo neperiano

Os dados foram submetidos à análise de variância, utilizando-se do software estatístico SISVAR-ESAL (Lavras MG). Os dados referentes às espécies de pinhão-manso, bravo e roxo, de caráter qualitativo foram analisados pelo teste de Tukey a 0,05 de probabilidade (Gomes,1985).

\section{Resultados E Discussão}

Na Tabela 2 estão os resultados da fenologia das espécies estudadas notando-se ser o Pinhão-roxo 'PR' a espécie mais precoce nas quatro fases fenológicas, seguida de pinhão-manso 'PM' e, por último, a de pinhão-bravo 'PB'. Esses resultados foram obtidos em condições de pluviosidade de $782,50 \mathrm{~mm}$, o que deve ter favorecido o crescimento e o desenvolvimento das três espécies de Jatropha uma vez que, segundo Saturnino et al

Tabela 2. Fenologia de plantas de pinhão-manso, bravo e roxo determinada em condições de campo*, durante período chuvoso

\begin{tabular}{lccc}
\hline \multicolumn{1}{c}{ Fase fenológica } & Pinhão-roxo & Pinhão-manso & $\begin{array}{c}\text { Pinhão-bravo } \\
\text { DAT (Mês/Ano) }\end{array}$ \\
DAT (Mês/Ano) & 120 (julho/09) \\
Estabelecimento/crescimento vegetativo & 41 (maio/09) & 75 (junho/09) & 121 (julho/09) \\
Inicio da floração & 42 (maio/09) & 76 (junho/09) & $152($ agosto/09) \\
Inicio da frutificação & 69 (junho/09) & 121 (julho/09) & 203 (outubro/09) \\
Inicio da maturação/colheita & 104 (julho/09) & 173 (setembro/09) & \\
\hline
\end{tabular}

\footnotetext{
* Mudas produzidas em viveiro e transplantadas para o campo aos 60 dias após transplantio (DAT)
} 
(2005), as plantas de pinhão-manso vegetam em regiões com 480 a $2.380 \mathrm{~mm}$ anuais de chuvas, com resultados melhores quando a taxa pluviométrica anual atinge valores superiores a $600 \mathrm{~mm}$.

Santos (2008) caracterizou o comportamento fenológico do pinhão-manso cultivado em campo experimental, com as coordenadas geográficas $9^{\circ} 27^{\prime} 57,3^{\prime \prime} \mathrm{S}$ e $35^{\circ} 49^{\prime} 57,4^{\prime \prime} \mathrm{W}$ e altitude de $127 \mathrm{~m}$, tendo constatado crescimento vegetativo com padrão sazonal, lento na estação seca e acelerado na estação chuvosa, com pico de floração e frutificação e ciclo reprodutivo médio de 120 dias, do surgimento da inflorescência até o amadurecimento pleno do fruto na planta. Nesta pesquisa observou-se, também na estação chuvosa, crescimento inicial acelerado, pico de floração e frutificação e ciclos reprodutivos médios de 62, 82 e 97 dias, do início da floração até o início da maturação/colheita, em pinhão-roxo, bravo e manso, respectivamente (Tabela 2). Portanto, fica caracterizada uma precocidade reprodutiva maior das três espécies de Jatropha em comparação com o ciclo reprodutivo do pinhão-manso, registrado por aquele autor.

O resumo da análise de variância e a comparação de médias para altura de planta das três espécies de Jatropha estão, na Tabela 3 ; ocorreu efeito altamente significativo $(\mathrm{p}<0,01)$ para o fator espécie (E) nos períodos avaliados, com exceção aos 105 DAT.

O pinhão-manso cresceu mais em altura nas primeiras avaliações mas, a partir de 135 DAT, destacou-se o pinhãobravo, situando-se o pinhão-roxo em posição mediana; Aos 75 DAT os valores de AP do pinhão-manso e do pinhão-roxo não diferem significativamente, ao contrário de pinhão-bravo, cuja altura foi relativamente inferior;aos 165 DAT, entretanto, o pinhão-bravo, que era a planta mais baixa, atingiu a maior altura dentre as três espécies, seguido do pinhão-roxo e do pinhão-manso (Tabela 3).

Constata-se, também, entre a primeira (15 DAT) e a última avaliação (165 DAT), ou seja, em 150 dias, crescimento acentuado em AP de pinhão-manso, bravo e roxo, com aumentos de 290, 1182 e 647\%, respectivamente; aos 165 DAT, menos de seis meses após transplante, as três espécies atingiram altura superior a $147 \mathrm{~cm}$ chegando a $220 \mathrm{~cm}$ a altura de pinhão-bravo; apenas relacionado ao pinhão-manso há também, na literatura, referências ao crescimento rápido da espécie, como relatado por Arruda et al. (2004) ao citarem que as plantas atingem altura de dois a três metros na idade adulta, podendo alcançar até cinco metros em condições favoráveis de clima e solo. Ratree (2004) observou, avaliando o crescimento do pinhão-manso na Tailândia, que mudas dessa espécie atingiram altura entre $83 \mathrm{e}$ $110 \mathrm{~cm}$, com 14 meses de idade.

Trabalhando em ambiente protegido, Nery et al. (2009) verificaram em pinhão-manso irrigado com água de baixa condutividade elétrica $\left(0,60 \mathrm{dS} \mathrm{m}^{-1}\right)$ no período entre $37 \mathrm{e}$ 142 DAS, crescimento similar em AP, com aumento em torno de $100 \mathrm{~cm}$ enquanto neste trabalho o acréscimo foi de 109 $\mathrm{cm}$ mas tendo as plantas da mesma espécie 23 dias a mais de idade; a diferença pode estar relacionada também ao tipo de cultivo, foram utilizados no estudo de Nery recipientes de 200 $\mathrm{L}$ de capacidade enquanto neste experimento o cultivo foi em condições de campo.

Com resultados também similares aos desta pesquisa, Silva et al. (2011) constataram, em plantas de pinhão manso bem supridas de umidade (reposição de água igual a $100 \%$ da evapotranspiração), aumento na altura das plantas alcançando aproximadamente $130 \mathrm{~cm}$ entre 18 e 144 dias após o transplantio.

O resumo da análise de variância e a comparação de médias para diâmetro caulinar (DC) das três espécies de Jatropha, estão na Tabela 4; constatou-se efeito significativo $(\mathrm{p}<0,01)$ do fator espécie (E), em todos os períodos avaliados.

A comparação das médias pelo teste de Tukey $(\mathrm{p}<0,05)$ para o DC de plantas das três espécies de Jatropha, está apresentada na Tabela 4 observando-se diferenças significativas entre elas nas seis avaliações realizadas (15 a 165 DAT). Constatou-se, aos 15 DAT, superioridade do pinhão-bravo (PB), em diâmetro caulinar (DC) diferindo significativamente do pinhão-manso (PM) e do pinhão-roxo (PR). As maiores médias de DC foram verificadas em pinhão-manso, entre 45 e 165 DAT, diferindo-o significativamente das outras duas espécies; na última avaliação, como exemplo, o DC do pinhão-manso foi $25 \%$ maior que o do pinhão-bravo e $38 \%$ maior que o de pinhão-roxo; neste mesmo período também foram verificadas diferenças significativas entre o pinhão-bravo e o roxo, com maiores valores de DC no primeiro $(\mathrm{PB})$.

Entre os períodos avaliativos de 15 a 165 DAT, com elevado crescimento inicial das plantas, constataram-se altos percentuais de aumento em diâmetro caulinar do pinhãomanso, bravo e roxo, da ordem de 346,28, 205,13 e 395,86\%, respectivamente (Tabela 4). Portanto, foi menor o aumento em diâmetro caulinar, do pinhão-bravo embora, como já discutido

Tabela 3. Resumo da análise de variância e comparação de médias para altura de planta (cm) do pinhão manso (PM), bravo (PB) e roxo (PR) no período chuvoso aos 15, 45, 75, 105, 135 e 165 dias após o transplantio - DAT

\begin{tabular}{|c|c|c|c|c|c|c|c|}
\hline \multirow{3}{*}{ CV } & \multirow{3}{*}{ GL } & \multicolumn{6}{|c|}{ Quadrados médios } \\
\hline & & \multicolumn{6}{|c|}{ Altura de planta - AP } \\
\hline & & 15 & 45 & 75 & 105 & 135 & 165 \\
\hline Espécie (E) & 2 & $1578,693^{* *}$ & $5392,083^{* *}$ & $1713,843^{\star *}$ & $72,871^{\mathrm{ns}}$ & $3713,260^{* *}$ & $21531,089^{* *}$ \\
\hline Bloco & 14 & $7,297^{\mathrm{ns}}$ & $93,786^{*}$ & $246,442^{*}$ & $693,261^{* *}$ & $982,748^{* *}$ & $635,912^{* *}$ \\
\hline Resíduo & 28 & 8,824 & 38,996 & 99,481 & 174,541 & 229,984 & 221,598 \\
\hline CV (\%) & & 11,00 & 9,72 & 10,69 & 10,49 & 9,46 & 8,32 \\
\hline Espécies & & \multicolumn{6}{|c|}{ Médias (cm) } \\
\hline Pinhão-manso (PM) & & $37,69 \mathrm{a}$ & $86,08 \mathrm{a}$ & $102,62 \mathrm{a}$ & $125,39 \mathrm{a}$ & 147,42 b & $147,18 \mathrm{c}$ \\
\hline Pinhão-bravo (PB) & & $17,23 \mathrm{c}$ & $51,79 \mathrm{~b}$ & $81,63 \mathrm{~b}$ & $124,04 \mathrm{a}$ & $177,80 \mathrm{a}$ & 220,85 a \\
\hline Pinhão-roxo (PR) & & $26,08 \mathrm{~b}$ & $54,90 \mathrm{~b}$ & 95,67 a & $128,35 \mathrm{a}$ & $155,52 \mathrm{~b}$ & $168,65 \mathrm{~b}$ \\
\hline d.m.s. & & 2,68 & $5,64 \mathrm{v}$ & 9,01 & 11,94 & 13,71 & 13,45 \\
\hline
\end{tabular}

${ }^{*}$ Significativo $(p<0,05),{ }^{* *}$ Significativo $(p<0,01)$ e ns não significativo, pelo teste F; d.m.s.: diferença mínima significativa, pelo Teste Tukey ( $<$ <,05); Médias, na vertical, seguidas pela mesma letra entre espécies, não diferem entre si, pelo teste de Tukey $(p<0,05)$. 
Tabela 4. Resumo da análise de variância e comparação de médias para diâmetro caulinar $(\mathrm{mm})$ do pinhão-manso (PM), bravo (PB) e roxo (PR) no período chuvoso aos 15, 45, 75, 105, 135 e 165 dias após o transplantio - DAT

\begin{tabular}{|c|c|c|c|c|c|c|c|}
\hline \multirow[b]{2}{*}{ CV } & \multirow[b]{2}{*}{ GL } & \multicolumn{6}{|c|}{ Quadrados médios } \\
\hline & & \multicolumn{6}{|c|}{ Diâmetro caulinar - DC } \\
\hline Espécie (E) & 2 & $307,335^{\star *}$ & $1287,355^{\star \star}$ & $1325,332^{* *}$ & $2745,966^{\star *}$ & $3150,427^{\star *}$ & $2828,266^{*}$ \\
\hline Resíduo & 28 & 0,923 & 2,729 & 9,346 & 7,943 & 10,622 & 14,161 \\
\hline CV (\%) & & 6,93 & 6,33 & 9,13 & 6,72 & 6,53 & 6,82 \\
\hline Espécies & & \multicolumn{6}{|c|}{ Médias (mm) } \\
\hline Pinhão-roxo (PR) & & $8,69 \mathrm{c}$ & $16,88 \mathrm{c}$ & $24,87 \mathrm{C}$ & $30,31 \mathrm{c}$ & $38,11 \mathrm{c}$ & $43,09 \mathrm{C}$ \\
\hline d.m.s. & & 0,87 & 1,49 & 2,76 & 2,55 & 2,95 & 3,40 \\
\hline
\end{tabular}

${ }^{*}$ Significativo $(p<0,05),{ }^{\star \star}$ Significativo $(p<0,01)$ e ns não significativo, pelo teste F; d.m.s. - diferença mínima significativa, pelo Teste Tukey ( $\left.p<0,05\right) ;$ Médias, na vertical, seguidas pela mesma letra entre espécies, não diferem entre si, pelo teste de Tukey $(p<0,05)$

(Tabela 3), tenha este genótipo atingido a maior altura dentre as espécies estudadas.

Na última avaliação, aos 165 DAT, verificou-se diâmetro caulinar 1,34 vez $(33,90 \%)$ maior em pinhão-manso do que em pinhão-bravo e $1,63 \mathrm{vez}(62,71 \%)$ maior do que em pinhãoroxo. Esta superioridade do pinhão-manso não foi verificada na discussão da variável AP (Tabela 3); aos 165 DAT o diâmetro do caule de PM chegou a 70,11 mm, cerca de 6,64 mm menor que o valor encontrado por Veras et al. (2011) pesquisando a mesma espécie, em lisímetros de drenagem a céu aberto e sob influência direta das chuvas; esses autores registraram, em plantas de PM irrigadas com água de boa qualidade $\left(0,60 \mathrm{dS} \mathrm{m}^{-1}\right)$, diâmetro do caule de $76,75 \mathrm{~mm}$ aos 210 dias após transplantio.

O resumo da análise de variância e a comparação de médias para a taxa de crescimento relativo em altura de plantas $\left(\mathrm{TCR}_{\mathrm{AP}}\right)$ das três espécies de Jatropha estão na Tabela 5. Ocorreu efeito significativo $(\mathrm{p}<0,01)$ para o fator espécie $(\mathrm{E})$, em todos os períodos avaliados (Tabela 5).

Nos cinco períodos avaliados observaram-se diferenças significativas da taxa de crescimento relativo em altura de plantas $\left(\mathrm{TCR}_{\mathrm{AP}}\right)$ entre as espécies. Em geral, o pinhão-bravo $(\mathrm{PB})$ se destacou em $\mathrm{TCR}_{\mathrm{AP}}$ sendo que aos 15-45 DAT não difere significativamente do pinhão-manso (PM) verificando-se o mesmo em relação ao pinhão-roxo, aos 45-75 DAT (Tabela 5).

Em geral, as espécies PM e PR não se diferenciaram na $\mathrm{TCR}_{\mathrm{AP}}$ nos vários períodos, excetuando-se a avaliação aos 4575 DAT, quando ocorreu superioridade do PR.
Como esperado, os valores de $\mathrm{TCR}_{\mathrm{AP}}$ diminuíram ao longo do tempo com reduções de 93,33, 80,00 e 92,31\%, entre a primeira e a última avaliação para pinhão-manso, bravo e roxo, respectivamente (Tabela 5). Isto ocorre porque, inicialmente, as plantas crescem com alto vigor, atingem pico de crescimento e em seguida canalizam suas energias para a fase produtiva, principalmente. Ratificando esta informação ao se verificar as fases fenológicas na Tabela 2, registraram-se plantas das três espécies de Jatropha em plena frutificação no mesmo período de ocorrência dos menores valores de $\mathrm{TCR}_{\mathrm{AP}}$, aos 135-165 DAT (Tabela 5).

$\mathrm{Na}$ última avaliação, aos 135-165 DAT, com $\mathrm{TCR}_{\mathrm{AP}} 3,5$ vezes maior do que os valores das outras duas espécies, o pinhão-bravo foi mais eficiente na formação de novos tecidos relacionados à altura de plantas, a partir dos pré-existentes, uma interpretação com base no próprio conceito de TCR (Tabela 5).

Os valores de TCR AP de pinhão-manso aos 15-45 DAT $\left(0,030 \mathrm{~cm} \mathrm{~cm}^{-1} \mathrm{~d}^{-1}\right)$ e aos $135-165$ DAT $\left(0,002 \mathrm{~cm} \mathrm{~cm}^{-1} \mathrm{~d}^{-1}\right)$ são de mesma magnitude aos obtidos por Silva et al. (2009) também em pinhão-manso em avaliações realizadas aos 18-60 DAT $\left(0,030 \mathrm{~cm} \mathrm{~cm}^{-1} \mathrm{~d}^{-1}\right)$ e aos $144-186$ DAT $\left(0,001 \mathrm{~cm} \mathrm{~cm}^{-1}\right.$ $\left.\mathrm{d}^{-1}\right)$, em parcelas recebendo irrigação correspondente a $100 \%$ da evapotranspiração da cultura, com redução de $0,001 \mathrm{~cm}$ $\left.\mathrm{cm}^{-1} \mathrm{~d}^{-1}\right)$.

Em referência à taxa de crescimento relativo em diâmetro caulinar $\left(\mathrm{TCR}_{\mathrm{DC}}\right)$, na Tabela 6 estão o resumo da análise de variância e a comparação de médias dessa variável nas três

Tabela 5. Resumo da análise de variância e comparação de médias para taxa de crescimento relativo em altura de plantas $\left(\mathrm{cm} \mathrm{cm}^{-1} \mathrm{~d}^{-1}\right)$ do pinhão-manso (PM), bravo (PB) e roxo (PR) no período chuvoso aos 15-45, 45-75, 75-105, 105-135 e 135-165 dias após o transplantio - DAT

\begin{tabular}{|c|c|c|c|c|c|c|}
\hline \multirow{3}{*}{ CV } & \multirow{3}{*}{ GL } & \multicolumn{5}{|c|}{ Quadrados médios } \\
\hline & & \multicolumn{5}{|c|}{ Taxa de crescimento rela tivo em altura de plantas $-T_{C} \mathrm{R}_{\mathrm{AP}}$} \\
\hline & & $15-45$ & $45-75$ & $75-105$ & $105-135$ & $135-165$ \\
\hline Espécie (E) & 2 & $0,00031^{* *}$ & $0,00026^{\star *}$ & $0,000080^{*}$ & $0,000085^{* *}$ & $0,000117^{* *}$ \\
\hline Bloco & 14 & $0,00004^{\mathrm{ns}}$ & $0,00001^{\mathrm{ns}}$ & $0,000005^{\mathrm{ns}}$ & $0,000005^{\mathrm{ns}}$ & $0,000009^{\text {ns }}$ \\
\hline Resíduo & 28 & 0,00005 & 0,00003 & 0,000007 & 0,000009 & 0,000005 \\
\hline CV $(\%)$ & & 23,44 & 37,03 & 27,39 & 37,89 & 61,68 \\
\hline Espécies & & \multicolumn{5}{|c|}{ Médias $\left(\mathrm{cm} \mathrm{cm}^{-1} \mathrm{~d}^{-1}\right)$} \\
\hline Pinhão-manso (PM) & & 0,030 ba & $0,009 \mathrm{~b}$ & $0,008 \mathrm{~b}$ & $0,007 \mathrm{~b}$ & $0,002 \mathrm{~b}$ \\
\hline Pinhão-bravo (PB) & & $0,035 \mathrm{a}$ & $0,016 \mathrm{a}$ & $0,012 \mathrm{a}$ & $0,011 \mathrm{a}$ & $0,007 \mathrm{a}$ \\
\hline Pinhão-roxo (PR) & & $0,026 \mathrm{~b}$ & $0,017 \mathrm{a}$ & $0,009 \mathrm{~b}$ & $0,006 \mathrm{~b}$ & $0,002 \mathrm{~b}$ \\
\hline d.m.s. & & 0,006 & 0,005 & 0,002 & 0,003 & 0,002 \\
\hline
\end{tabular}

${ }^{*}$ Significativo $(p<0,05),{ }^{* *}$ Significativo $(p<0,01) e^{\text {ns }}$ não significativo, pelo teste F; d.m.s.: diferença mínima significativa, pelo teste Tukey ( $\left.<<0,05\right)$; Médias, na vertical, seguidas pela mesma letra entre espécies, não diferem entre si, pelo teste de Tukey $(p<0,05)$ 
Tabela 6. Resumo da análise de variância e comparação de médias para taxa de crescimento relativo em diâmetro caulinar $\left(\mathrm{mm} \mathrm{mm}^{-1} \mathrm{~d}^{-1}\right)$ do pinhão manso (PM), bravo (PB) e roxo (PR) no período chuvoso aos 15-45, 45-75, 75-105, 105-135 e 135-165 dias após o transplantio - DAT

\begin{tabular}{|c|c|c|c|c|c|c|}
\hline \multirow[b]{2}{*}{ CV } & \multirow[b]{2}{*}{ GL } & \multicolumn{5}{|c|}{ Quadrados médios } \\
\hline & & \multicolumn{5}{|c|}{ Taxa de crescimento rela tivo caulinar em diâmetro $-\mathrm{TCR}_{\mathrm{DC}}$} \\
\hline Espécie (E) & 2 & $0,00032^{* *}$ & $0,000132^{* *}$ & $0,000008^{\text {ns }}$ & $0,000018^{* *}$ & $0,000005^{\mathrm{ns}}$ \\
\hline Resíduo & 28 & 0,00003 & 0,000007 & 0,000004 & 0,000003 & 0,000003 \\
\hline CV (\%) & & 26,81 & 27,60 & 26,76 & 28,97 & 52,45 \\
\hline Espécies & & \multicolumn{5}{|c|}{ Médias $\left(\mathrm{mm} \mathrm{mm}^{-1} \mathrm{~d}^{-1}\right)$} \\
\hline Pinhão-roxo (PR) & & $0,023 \mathrm{a}$ & $0,013 \mathrm{a}$ & $0,007 \mathrm{a}$ & $0,007 \mathrm{a}$ & $0,003 a$ \\
\hline d.m.s. & & 0,005 & 0,002 & 0,002 & 0,001 & 0,002 \\
\hline
\end{tabular}

${ }^{*}$ Significativo $(p<0,05),{ }^{* *}$ Significativo $(p<0,01)$ e ns não significativo, pelo teste F; d.m.s. - diferença mínima significativa, pelo teste Tukey $(p<0,05)$; Médias, na vertical, seguidas pela mesma letra entre espécies, não diferem entre si, pelo teste de Tukey $(p<0,05)$

espécies de Jatropha. Ocorreu efeito significativo do fator espécie (E) nos períodos 15-45, 45-75 e 105-135 DAT (Tabela 6).

De acordo com a Tabela 6 registraram-se, aos $15-45,45-$ 75 e 105-135 DAT, diferenças significativas entre as taxas de crescimento relativo em diâmetro caulinar $\left(\mathrm{TCR}_{\mathrm{DC}}\right)$ das espécies, ou seja, as três oleaginosas diferem com relação à eficiência na formação de novos tecidos (relacionados ao diâmetro das plantas), a partir dos pré-existentes; nos outros dois períodos (75-105 e 135-165 DAT), foram similares os valores de $\mathrm{TCR}_{\mathrm{DC}}$, sem diferença significativa entre elas.

Nota-se também redução de $\mathrm{TCR}_{\mathrm{DC}}$ ao longo do tempo para as três espécies de Jatropha, o que é natural, considerando-se que, em geral, o crescimento de plantas é mais lento com a progressão da idade, quando elas têm um número maior de ramos e de tecidos novos para alocação de foto assimilados (Cuellar-Ortiz et al., 2008; Srivastava et al., 2009). Como explicado antes, quando se abordou a Tabela 5 , que trata de TCR AP, as reduções coincidiram com o início de fases reprodutivas (Tabela 2), limitando a partição de energias para as variáveis de crescimento.

Entre a primeira e a última avaliação as taxas de crescimento relativo em diâmetro caulinar para pinhão-manso, bravo e roxo, decresceram $0,021,0,012 \mathrm{e} 0,020 \mathrm{~mm} \mathrm{~mm}^{-1} \mathrm{~d}^{-1}$, respectivamente, correspondendo às reduções de $87,50,75,00 \mathrm{e} 86,96 \%$, para as três espécies (Tabela 6). De forma similar, Silva (2009) verificou no tratamento controle trabalhando apenas com pinhão-manso, (disponibilidade hídrica igual a $100 \%$ da evapotranspiração da cultura), decréscimo na $\mathrm{TCR}_{\mathrm{DC}}$ ao longo do tempo, de $0,022 \mathrm{~mm}$ $\mathrm{mm}^{-1} \mathrm{~d}^{-1}$, entre 18-60 e 144-186 DAT, ou seja, uma redução de $92,43 \%$, valor superior ao verificado neste trabalho passível de ser explicado pelo aumento da idade das plantas.

\section{Conclusões}

1. As fases fenológicas do pinhão-manso, bravo e roxo, diferem cronologicamente.

2. Até 165 dias após o transplantio as plantas de pinhãobravo crescem mais em altura e as de pinhão-manso em diâmetro caulinar.

3. As maiores taxas de crescimento relativo em altura de plantas ocorrem na fase de crescimento vegetativo, com pinhãobravo mais eficiente do que o manso e o roxo.
4. Em diâmetro caulinar as maiores taxas de crescimento relativo ocorrem na fase de crescimento vegetativo, com pinhãomanso mais eficiente do que o roxo e bravo.

5. As menores taxas de crescimento relativo em altura de plantas e diâmetro caulinar em pinhão-manso, bravo e roxo, coincidem com as fases reprodutivas das plantas.

\section{Literatura Citada}

Albuquerque, U. P. de; Andrade, L. H. C. Conhecimento botânico tradicional e conservação em uma área de Caatinga no Estado de Pernambuco, nordeste do Brasil. Acta Botânica Brasileira. v.16, p.273-285, 2002.

Arruda, F. P. de.; Beltrão, N. E. de M.; Andrade, A, P. de.; Pereira, W. E.; Severino, L. S. Cultivo de pinhão-manso (Jatropha curcas L.) como alternativa para o Semi-Árido nordestino. Revista Brasileira de Oleaginosas e Fibrosas, v.8, p.789-799, 2004.

Augustus, G. D. P. S.; Jayabala, N. M.; Seilerb, G. J. Evaluation and bio induction of energy components of Jatropha curcas. Biomass and Bioenergy, v.23, p.161-164, 2002.

Benincasa, M. M. P. Análise de crescimento de plantas. Jaboticabal: FUNEP, 2003. 41p

Cuellar-Ortiz, S. M.; Arrieta, M. D. L. P.; Acosta-Gallegos, J.; Covarrubias, A. A. Relationship between carbohydrate partitioning and drought resistance in common bean. Plant Cell Environment, v.31, p.1399-1409, 2008.

Fisch, S. T. V.; Nogueira Júnior, L. R.; Mantovani, W. Fenologia reprodutiva de Euterpe edulis Mart. na Mata Atlântica (Reserva ecológica do Trabiju, Pindamonhangaba - SP). Revista Biociência de Taubaté, v.6, p.31-37, 2000.

Folgarait, P. J.; Patrock, R. J. W.; Gilbert, L. E. The infuence of ambient conditions and space on the phenological patterns of a Solenopsis phorid guild in an arid environment. Biological Control, v.42, p.262-273, 2007.

Francis, G.; Edinger, R.; Becker, K. A concept for simultaneous wasteland reclamation, fuel production, and socio-economic development in degraded areas in India: Need, potencial and perspectives of Jatropha plantations. Natural Resources Fórum. v.29, p.12-24, 2005.

Gomes, F. P. Curso de estatística experimental. 11.ed. Piracicaba: ESALQ/USP, Nobel, 1985. 466p. 
Nery, A. R. Crescimento e desenvolvimento do pinhão-manso irrigado com águas salinas sob ambiente protegido. Campina Grande: UFCG, 2008. 116p. Dissertação Mestrado

Nery, A. R.; Rodrigues, L. N.; Silva, M. B. R. da; Fernandes, P. D.; Chaves, L. H. G.; Dantas Neto, J.; Gheyi, H. R. Crescimento do pinhão-manso irrigado com águas salinas em ambiente protegido. Revista Brasileira de Engenharia Agrícola e Ambiental, v.13,p.551-558,2009.

Ratree, S. A. Preliminary study on physic nut Jatropha curcas in Thailand. Journal of Biogical Sciences, v.7, p.1620-1623, 2004.

Santos, C. M. Fenologia e capacidade fotossintética do pinhãomanso (Jatropha curcas L.) em diferentes épocas do ano no estado de Alagoas. Rio Largo: UFAL, 2008. 67p. Dissertação Mestrado

Saturnino, H. M.; Pacheco, D. D.; Kakida, J.; Tominaga, N.; Gonçalves, N. P. Cultura do pinhão-manso (Jatropha curcas L.). Informe Agropecuário, v.26, p.44-78, 2005.

Silva, M. B. R. da. Crescimento, desenvolvimento e produção do pinhão-manso irrigado com água residuária em função da evapotranspiração. Campina Grande: UFCG, 2009. 151p. Tese Doutorado
Silva, M. B. R. da; Fernandes, P. D.; Dantas Neto, J.; Nery, A. R.; Rodrigues, L. N.; Viégas, R. A. Crescimento e produção do pinhão-manso irrigado com água residuária sob condições de estresse hídrico. Revista Brasileira de Engenharia Agrícola e Ambiental, v.15, p.621-629, 2011.

Srivastava, A. C.; Ganesan, S.; Ismail, I. O.; Ayre, B. G. Effective carbon partitioning driven by exotic phloemspecific regulatory elements fused to the Arabidopsis thaliana AtSUC2 sucrose-proton symporter gene. BMC Plant Biology, v.20, p.97-110, 2009.

Urquiaga, S.; Alves, B. J. R.; Boodey, R. M. Produção de biocombustíveis, a questão do balanço energético. Revista de Política Agrícola, v.14, p.42-46, 2005.

Veras, R. P.; Laime, E. M. O.; Fernandes, P. D.; Soares, F. A. L.; Freire, E. A. Altura de planta, diâmetro caulinar e produção do pinhão-manso sob diferentes níveis de salinidade. Revista Brasileira de Engenharia Agrícola e Ambiental, v.15, p.582587, 2011. 